\title{
Supercapacitor Electrodes from the in Situ Reaction between Two-Dimensional Sheets of Black Phosphorus and Graphene Oxide
}

DOI:

10.1021/acsami.7b18853

\section{Document Version}

Accepted author manuscript

Link to publication record in Manchester Research Explorer

Citation for published version (APA):

Cao, J., He, P., Brent, J. R., Yilmaz, H., Lewis, D. J., Kinloch, I. A., \& Derby, B. (2018). Supercapacitor Electrodes from the in Situ Reaction between Two-Dimensional Sheets of Black Phosphorus and Graphene Oxide. ACS Applied Materials and Interfaces, 10(2), 10330-10338. https://doi.org/10.1021/acsami.7b18853

Published in:

ACS Applied Materials and Interfaces

\section{Citing this paper}

Please note that where the full-text provided on Manchester Research Explorer is the Author Accepted Manuscript or Proof version this may differ from the final Published version. If citing, it is advised that you check and use the publisher's definitive version.

\section{General rights}

Copyright and moral rights for the publications made accessible in the Research Explorer are retained by the authors and/or other copyright owners and it is a condition of accessing publications that users recognise and abide by the legal requirements associated with these rights.

\section{Takedown policy}

If you believe that this document breaches copyright please refer to the University of Manchester's Takedown Procedures [http://man.ac.uk/04Y6Bo] or contact uml.scholarlycommunications@manchester.ac.uk providing relevant details, so we can investigate your claim.

\section{OPEN ACCESS}




\section{Supercapacitor electrodes from the in situ reaction between 2D}

\section{sheets of black phosphorus and graphene oxide}

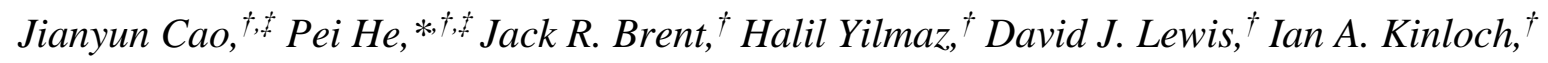
and Brian Derby ${ }^{*}+$

†School of Materials, University of Manchester, Oxford Road, Manchester M13 9PL, U.K.

These authors contributed equally

Email: pei.he@manchester.ac.uk; brian.derby@manchester.ac.uk

KEYWORDS: graphene oxide, black phosphorus, degradation, liquid electrolyte, supercapacitors 


\begin{abstract}
2D materials show considerable promise as high surface area electrodes for energy storage applications such as supercapacitors. A single sheet of graphene possesses a large specific surface area due to its atomically thin thickness. However, in order to package this area efficiently in a device, it must be confined within a finite 3D volume without restacking of the sheet faces. Herein we present a method of maintaining the high surface area through the use of a hybrid thin film in which few-layer exfoliated black phosphorus (BP) reduces graphene oxide (GO) flakes. When the film is exposed to moisture, a redox reaction between the $\mathrm{BP}$ and the $\mathrm{GO}$ forms an interpenetrating network of reduced graphene oxide (RGO) and a liquid electrolyte of intermediate phosphorus acids $\mathrm{H}_{x} \mathrm{PO}_{y}$. The presence of the liquid $\mathrm{H}_{x} \mathrm{PO}_{y}$ electrolyte in the $\mathrm{RGO} / \mathrm{H}_{x} \mathrm{PO}_{y}$ film stabilizes and preserves an open channel structure enabling rapid ion diffusion, leading to an excellent charging rate capability (up to $500 \mathrm{mV}$ $\mathrm{s}^{-1}$, and retaining $62.3 \%$ of initial capacitance at a large current density of $50 \mathrm{~A} \mathrm{~g}^{-1}$ ) when used as electrodes in supercapacitors.
\end{abstract}




\section{INTRODUCTION}

Graphene oxide (GO) is a single layer graphene sheet functionalized with oxygen groups, various macroscale structures can be fabricated by using GO sheets as basic building blocks, such as film, paper, fiber, hydrogel, aerogel, etc. ${ }^{1-3}$ Reduction of GO leads to reduced graphene oxide (RGO) with much greater electrical conductivity. ${ }^{4-5}$ Graphene films, assembled from overlapping RGO sheets, show high electrical conductivity $\left(\sim 7200 \mathrm{~S} \mathrm{~m}^{-1}\right)$ and good mechanical strength (150 MPa in tension), ${ }^{6-7}$ and have been widely studied as electrode materials for electrochemical supercapacitors. ${ }^{8-11}$ However, during film deposition and drying, compact face-on-face restacking of graphene sheets may occur. This both reduces the surface area and limits the rapid transport of electrolyte ions into the inner structure of the graphene film, leading to a reduction in electrochemical performance, particularly rate capability. ${ }^{10}$ Restacking of graphene sheets is typically prevented by inserting spacers between the graphene sheets, e.g. metal or metal oxide nanoparticles, carbon nanotubes and carbon black. ${ }^{12-14}$ Another approach to prevent graphene restacking is to use the principles of colloid chemistry to maintain a stable liquid phase between the graphene layers. ${ }^{10-11}$ The colloidal approach has been demonstrated with chemically modified or reduced graphene oxide (RGO) where non-planar sheets of graphene containing oxygen defects interact with the surrounding solvent molecules preventing face-face contact. Even after the removal of the majority of the solvent phase, a hybrid material of non-planar graphene sheets separated by stable, nanometer thick, bound solvent layers has been reported. ${ }^{10}$ Further study has demonstrated that by using a mixture of two liquids (e.g. water in sulfuric acid solution), a liquid electrolyte (in this case sulfuric acid) can be retained inside the graphene film. ${ }^{11}$ This not only prevents restacking of the graphene sheets in an electrode but also provides the electrolyte required for charging and discharging a supercapacitor, leading to improved rate capability. 
2D Black phosphorus (BP) has attracted considerable interests from the research community due to its extraordinary electrical and optoelectronic properties. ${ }^{15-19}$ However, it is well established that mono- or few-layer BP, produced by both mechanical exfoliation and solution phase exfoliation, is unstable and degrades in the presence of oxygen and water under ambient conditions, ${ }^{20-23}$ to form phosphorus acids. However, despite extensive experimental and theoretical studies, ${ }^{22-26}$ the detailed mechanisms of the degradation of BP remain unconfirmed, as are the precise degradation products. Recent studies have shown that this reaction finally forms phosphorus containing acids, such as phosphorous acid $\left(\mathrm{H}_{3} \mathrm{PO}_{3}\right){ }^{22}$ phosphoric acid $\left(\mathrm{H}_{3} \mathrm{PO}_{4}\right),{ }^{23-24}$ or a mixture of $\mathrm{H}_{3} \mathrm{PO}_{3}$ and $\mathrm{H}_{3} \mathrm{PO}_{4},{ }^{25}$ while the intermediate compounds might contain hypophosphorous acid $\left(\mathrm{H}_{3} \mathrm{PO}_{2}\right) .{ }^{25}$ Previous research has shown that hypophosphorous acid is capable of reducing graphene oxide (GO), with the as-reduced GO film exhibiting an electrical conductivity of $380 \mathrm{~S} \mathrm{~m}^{-1} \cdot{ }^{27}$ Here we report on a combination of $\mathrm{GO}$ with $\mathrm{BP}$ into a hybrid material $(\mathrm{GO} / \mathrm{BP})$, in which the $\mathrm{BP}$ acts both as a spacer to prevent the stacking of GO sheets and also, as a reducing agent in the presence of $\mathrm{H}_{2} \mathrm{O}$, to chemically modify the $\mathrm{GO}$ to $\mathrm{RGO}$ sheets. A product of the interaction of $\mathrm{H}_{2} \mathrm{O}$ with $\mathrm{BP}$ is a complex solution of phosphorous containing acids $\left(\mathrm{H}_{x} \mathrm{PO}_{y}\right),{ }^{22,24-25}$ it is hypothesized that this will produce an electrolyte that may be capable of stabilizing the RGO sheets through colloidal processes to prevent their stacking. ${ }^{10-11}$ The as-formed RGO film stabilized by $\mathrm{H}_{x} \mathrm{PO}_{y}$ electrolyte $\left(\mathrm{RGO} / \mathrm{H}_{x} \mathrm{PO}_{y}\right)$ has been studied as electrode materials for supercapacitors in this work.

\section{EXPERIMENTAL SECTION}

Preparation of GO/BP hybrid film: BP crystal was purchased from Smart Elements (Vienna, Austria). Natural graphite flakes (Grade 9842) were purchased from Graphexel Ltd., (Epping, 
UK). Concentrated $\mathrm{H}_{2} \mathrm{SO}_{4}(>17.7 \mathrm{~mol}$ ) was purchased from Fisher Scientific (Loughborough, UK). All other chemicals were purchased form Sigma-Aldrich (Gillingham, Dorset, UK). Few layer BP flakes were prepared by liquid phase exfoliation. ${ }^{15} \mathrm{GO}$ flakes were prepared by the modified Hummers' method. ${ }^{28}$ The GO/BP hybrid film was prepared by vacuum filtration of a mixed dispersion of $\mathrm{GO}$ and $\mathrm{BP}$ flakes. Briefly, $0.22 \mathrm{~mL}$ of concentrated $\mathrm{GO}$ dispersion (3.5 mg mL $\mathrm{m}^{-1}$ ) in absolute ethanol was mixed with $2 \mathrm{~mL}$ BP flakes dispersion in acetonitrile $\left(0.2 \mathrm{mg} \mathrm{mL} \mathrm{m}^{-1}\right)$. After mixing, the mixture was diluted with acetonitrile to a total volume of 30 $\mathrm{mL}$. The mass ratio of GO to BP is 2 to 1 . The mixed dispersion was subjected to bath sonication for $30 \mathrm{~min}$ and the solvent removed by vacuum filtration with a PTFE filter membrane (Omnipore, $0.1 \mu \mathrm{m}$ pore size, $25 \mathrm{~mm}$ diameter). After filtration, the GO/BP hybrid film was peeled from the filter membrane in absolute ethanol and used in further experiments.

Preparation of $R G O / H_{x} P O_{y}$ film: Transformation of the GO/BP hybrid film to a $\mathrm{RGO} / \mathrm{H}_{x} \mathrm{PO}_{y}$ film was achieved by exposing the GO/BP hybrid film to $100 \%$ humidity at $25{ }^{\circ} \mathrm{C}$ for $120 \mathrm{~h}$. The $100 \%$ humidity environment was achieved inside an enclosed VWB 18 water bath chamber (VWR, Soulbury, UK) with one third of its volume filled with de-ionized water at $25{ }^{\circ} \mathrm{C}$, and the GO/BP hybrid film placed in the humid atmosphere above the water level. The humidity level was monitored with a commercial humidity sensor (ST-321 Humidity Meter: Farnell Element 14, Leeds UK). Finally, the as-formed $\mathrm{RGO} / \mathrm{H}_{x} \mathrm{PO}_{y}$ film was put into the vacuum oven (Fistreem, Loughborough, UK) with a vacuum of $\sim 13$ mbar at room temperature to evaporate the absorbed water. For a control specimen, a pure RGO film was prepared by soaking the $\mathrm{RGO} / \mathrm{H}_{x} \mathrm{PO}_{y}$ film in de-ionized water to remove the as-formed $\mathrm{H}_{x} \mathrm{PO}_{y}$ acids. This RGO film was also vacuum treated, following the same procedure as the $\mathrm{RGO} / \mathrm{H}_{x} \mathrm{PO}_{y}$ film, to remove any water trapped between the RGO layers. 
Material and film characterization: The morphology of the GO sheets was characterized by a Dimension 3100 atomic force microscope (AFM) (Bruker, Bilericca, MA, USA) using tapping-mode imaging. Scanning electron microscope (SEM) images and enery dispersive Xray elemental analyses (EDX) were obtained using a Zeiss Sigma VP field emission SEM (Carl Zeiss, Jena, Germany). Transmission electron microscopy (TEM) characterization was conducted with a CM20 TEM (FEI, Eindhoven, Netherlands). X-ray diffraction (XRD) characterization was conducted with a X'Pert Pro X'Celerator diffractometer (PANalytical: Almelo, Netherlands). Raman spectroscopy was performed on a Renishaw 1000 spectrometer with an excitation laser wavelength of $633 \mathrm{~nm}$, curve fitting was conducted by Wire 4.1 software with Lorentz functions. Fourier transform infrared spectrum (FT-IR) was measured with a Nicolet 5700 spectrometer (Thermo Fisher Scientific, Waltham. MA, USA). X-ray photoelectron spectroscopy (XPS) was performed with a Kratos Axis Ultra X-ray photoelectron spectrometer meter (Kratos, Manchester, UK); curve fitting was accomplished by CasaXPS software. Contact angle measurement was carried out by a Krüss Drop Shape Analyzer DSA100 (Krüss, Hamburg, Germany). The sheet resistance of RGO film was measured using a Jandel four-probe station (Jandel Engineering, Linslade, UK) equipped with a Keithley 2182A nanovoltmeter and a Keithley 6220 current source (Keithley Tektronix, Beaverton, USA), .

Fabrication of supercapacitors based on $R G O / H_{x} P O_{y}$ film: Supercapacitor based on $\mathrm{RGO} / \mathrm{H}_{x} \mathrm{PO}$ film was assembled by two pieces of $\mathrm{RGO} / \mathrm{H}_{x} \mathrm{PO}_{y}$ film with a piece of PTFE filter membrane (Omnipore, $0.2 \mu \mathrm{m}$ pore size) as separator. Prior to assembly, the $\mathrm{RGO} / \mathrm{H}_{x} \mathrm{PO}_{y}$ films and PTFE filter membrane were soaked in $1 \mathrm{M} \mathrm{H}_{3} \mathrm{PO}_{4}$ overnight. As control experiment, supercapacitor was also fabricated by the RGO film which the as-formed 
$\mathrm{H}_{x} \mathrm{PO}_{y}$ acids electrolyte has been washed away. All electrochemical experiments were carried out using an electrochemical workstation, Ivium Stat (Ivium Technologies, Eindhoven, Netherlands). The specific capacitance $(C)$ of the materials $\left(\mathrm{F}^{-1}\right)$ based on galvanostatic discharge is calculated as follows ${ }^{29-30}$ :

$$
\begin{aligned}
& C=\frac{I \Delta t}{m \Delta V} \\
& C=4 C_{\text {cell }}
\end{aligned}
$$

where $C_{\text {cell }}$ is the capacitance per total mass of the two electrodes in the cell $\left(\mathrm{F} \mathrm{g}^{-1}\right), I$ is the discharge current (A), $\Delta t$ is the discharge time (s), $\Delta V$ is the operating potential/cell voltage range excluding the IR drop (V), $m$ is the total mass of active materials in the two electrodes.

The energy density of the supercapacitor was calculated as follows ${ }^{29}$ :

$$
\begin{aligned}
& E=\frac{1}{2} C_{\text {cell }} V^{2} \\
& P=\frac{E}{\Delta t}
\end{aligned}
$$

Where $E$ is the energy density $\left(\mathrm{Wh} \mathrm{kg}^{-1}\right), V$ is the working cell voltage $(\mathrm{V}), P$ is the power density $\left(\mathrm{W} \mathrm{kg}^{-1}\right)$. 

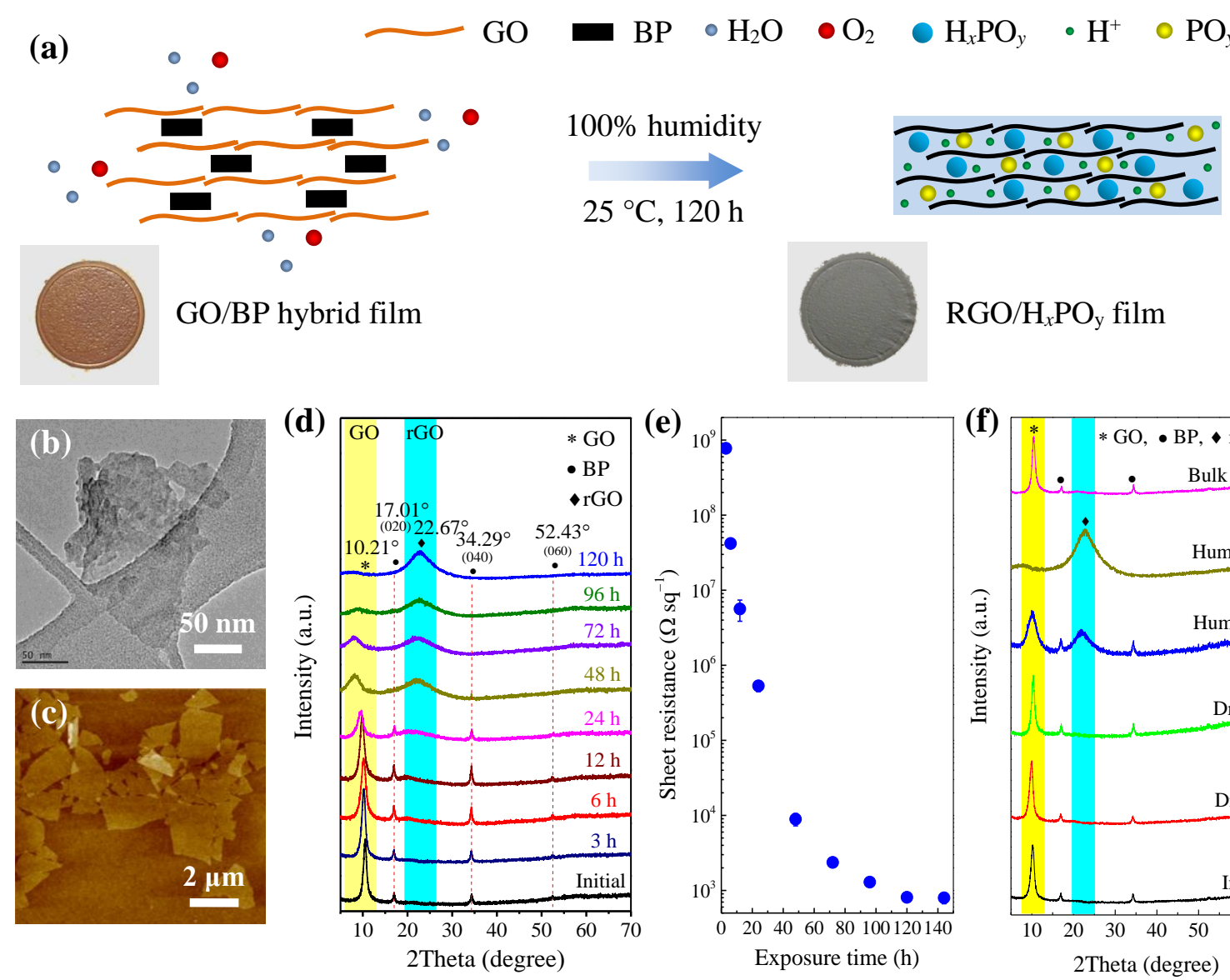

$\mathrm{RGO} / \mathrm{H}_{x} \mathrm{PO}_{\mathrm{y}}$ film

(d)
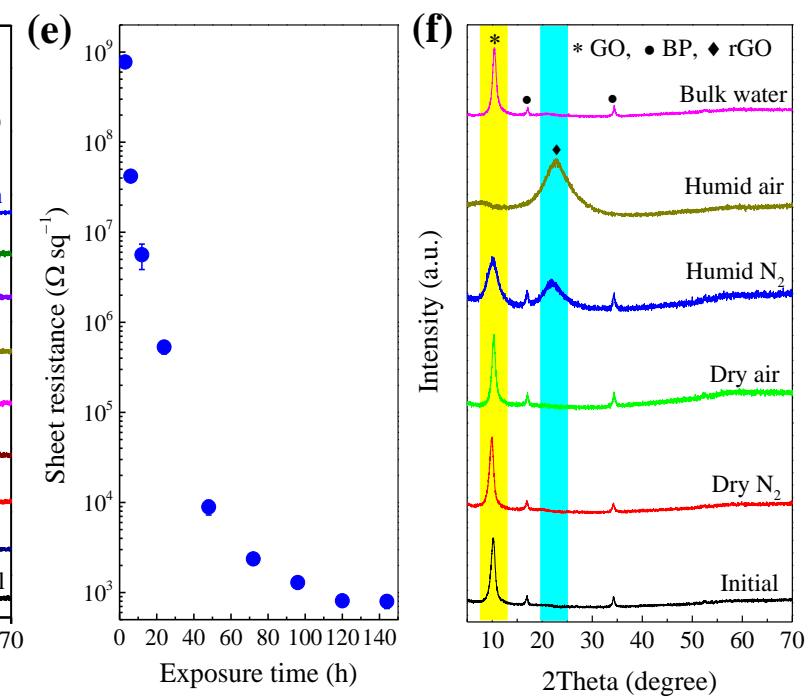

Figure 1. (a) Schematic illustration of the in situ reduction of GO by BP and formation of $\mathrm{H}_{x} \mathrm{PO}_{y}$ electrolyte, the left and right photographs show the initial GO/BP hybrid film and the as-formed $\mathrm{RGO} / \mathrm{H}_{x} \mathrm{PO}_{y}$ film, respectively. (b) TEM image of liquid phase exfoliated few layer BP flakes. (c) AFM image of GO sheets. (d) Evolution of the XRD pattern obtained from the GO/BP hybrid film with increasing time of exposure to $100 \%$ humidity at $25{ }^{\circ} \mathrm{C}$. (e) Evolution of the sheet resistance of the GO/BP hybrid film with increasing time of exposure to $100 \%$ humidity at $25^{\circ} \mathrm{C}$. (f) XRD patterns of the GO/BP hybrid film after being exposed to a range of environments at $25^{\circ} \mathrm{C}$ for $120 \mathrm{~h}$. 


\section{RESULTS AND DISSCUSSION}

Hybrid films of GO and BP were prepared by the vacuum filtration of a mixed dispersion of nanosheets of the materials. Figure 1a shows a schematic illustration of the proposed transformation of the GO/BP hybrid film to a $\mathrm{RGO} / \mathrm{H}_{x} \mathrm{PO}_{y}$ film through a redox reaction between the BP and GO. This is accompanied by a change in colour of the GO/BP hybrid film from brown to black. Figure $1 \mathrm{~b}$ shows a typical TEM image of the BP flakes produced by the liquid exfoliation method, reported earlier by Brent et al. ${ }^{15}$ The as-exfoliated BP has an average size of $72 \pm 30 \mathrm{~nm}$, with most flakes being 50 100 nm in diameter (see Figure S1 for other TEM images of BP flakes and the flake size distribution). According to the AFM characterization (Figure S2), the thicknesses of the exfoliated BP flakes are generally below 6 $\mathrm{nm}$, with a mean thickness of $3.3 \pm 1.2 \mathrm{~nm}$, suggesting the flakes are predominantly 3 layers. ${ }^{15}$ Figure 1c shows a typical AFM image of GO flakes, further analysis found a mean lateral diameter of $1.33 \pm 0.45 \mu \mathrm{m}$ with the majority of the flakes were in the size range $1 \sim 2$ $\mu \mathrm{m}$ (Figure S3c). Height profile of a GO flake is show in Figure S3b, suggesting a thickness of $\sim 1 \mathrm{~nm}$. Statistically analyzing $100 \mathrm{GO}$ flakes (see Figure S3d for the thickness distribution) lead to a mean thickness of $1.04 \pm 0.1 \mathrm{~nm}$, and all flakes are below $1.5 \mathrm{~nm}$ in thickness, indicating the GO flakes are predominantly single layer.

Figure 1d shows a sequence of XRD patterns taken from the hybrid film after exposure to air at $100 \%$ relative humidity for periods of up to $120 \mathrm{~h}$. The diffraction peaks from the initial $\mathrm{GO} / \mathrm{BP}$ hybrid film at $17.01^{\circ}, 34.29^{\circ}$ and $52.43^{\circ}$, are assigned to BP reflections from $(020)$, (040) and (060) planes respectively; a strong GO peak is also visible at $10.21^{\circ}$ (see Supporting Information Figure S4 for the XRD pattern from a pure BP crystal). As the time of exposure to the humid environment increases, the intensity of the BP and GO reflections decreases. Interestingly, the GO peak reflection angle $(2 \theta)$ decreases from $10.21^{\circ}$ to $8.24^{\circ}$ 
after $24 \mathrm{~h}$ exposure, suggesting that the GO sheets are swelling due to the intercalation of water molecules. ${ }^{31}$ After $24 \mathrm{~h}$ exposure, there is a considerable reduction in the intensity of the BP peaks and the emergence of a peak at $2 \theta=22.67^{\circ}$, which is assigned to RGO. ${ }^{6}$ The diffraction peaks for BP disappear after $48 \mathrm{~h}$ exposure, however, the reduction in the GO peak and a parallel increase in the RGO peak continue beyond this time before reaching equilibrium after about $120 \mathrm{~h}$. We interpret that the continued reduction of the GO reflection angle as its intensity decreases indicates the continued swelling of the GO galleries, allowing gradual access of the $\mathrm{H}_{x} \mathrm{PO}_{y}$ produced by the degradation of BP to an increasing large area of the GO. When reduction of the GO commences, it reduces the $\mathrm{H}_{x} \mathrm{PO}_{y}$ concentration of the electrolyte, driving further degradation of the BP. Once all the BP has been consumed, reduction of the GO to $\mathrm{RGO}$ can continue until the $\mathrm{H}_{3} \mathrm{PO}_{2}$ content of the electrolyte is consumed or the GO has been fully reduced, thus explaining the continuing change in the GO and RGO peak intensities after the disappearance of the BP diffraction peaks.

Further evidence for the reduction of GO is provided by monitoring the evolution of the sheet resistance of the GO/BP hybrid film with increasing time of exposure to $100 \%$ humidity air (Figure 1e). The sheet resistance of the GO/BP hybrid film drops monotonically by six orders of magnitude with increasing exposure time. After $120 \mathrm{~h}$, the sheet resistance of the asformed $\mathrm{RGO} / \mathrm{H}_{x} \mathrm{PO}_{y}$ film is $796 \pm 92 \Omega \mathrm{sq}^{-1}$, corresponding to an electrical conductivity of $837 \pm 98 \mathrm{~S} \mathrm{~m}^{-1}$ (film thickness of $\left.\sim 1.5 \mu \mathrm{m}\right)$.

To further investigate the role of $\mathrm{O}_{2}$ and $\mathrm{H}_{2} \mathrm{O}$ in the transformation of the GO/BP hybrid film, XRD patterns were obtained from the GO/BP films after $120 \mathrm{~h}$ exposure to various environments and conditions, as shown in Figure 1f. There is almost no visible change in the relative intensity of the peaks in the XRD pattern, when compared with the as-received state, 
after the GO/BP hybrid film is exposed to dry $\mathrm{N}_{2}$ or dry air. However, exposure of the GO/BP film to $100 \%$ humid $\mathrm{N}_{2}$ leads to the weakening of peaks corresponding to GO and BP and the appearance of a new broad peak corresponding to RGO. These results suggest that the presence of $\mathrm{H}_{2} \mathrm{O}$ dominates the BP degradation mechanism and assists the reduction of GO. The change after exposure to humid $\mathrm{N}_{2}$ is less marked that that seen after exposure to humid air, indicating that the presence of $\mathrm{O}_{2}$ accelerates this process. The degradation of BP in the presence of water but without oxygen is consistent with previous observations and predictions. ${ }^{17}$ Note that the XRD pattern obtained from a GO/BP hybrid film immersed in liquid water shows the degradation of BP, but with no apparent change to the GO peak. This is likely to be the result of the excess water diluting the $\mathrm{H}_{x} \mathrm{PO}_{y}$ electrolyte diminishing its effectiveness in reducing the GO. Table $\mathrm{S} 1$ in the supplementary information summarizes the extent of transformation of the GO/BP hybrid films under various environments.

Raman spectroscopy was also used to track the reduction of GO in this work, 5 spectra were recorded from each sample at random locations, the recorded spectra were fitted by Lorentz functions at a range of 1000 to $2000 \mathrm{~cm}^{-1}$, thus the intensity (I) and full width at halfmaximum (FWHM, plotted as $\Gamma$ ) of $\mathrm{G}$ and D bands can be analyzed, see Figure S5a for the examples of fitted spectra for the initial GO/BP film and the film with $72 \mathrm{~h}$ of exposure. Based on previous reports, ${ }^{32} \mathrm{GO}$ prepared using Hummer's method are highly defective, thus no significant change in the Raman spectra is expected after reduction. Consistent with this, Raman spectra from the GO/BP hybrid film after various times of exposure to $100 \%$ humidity (Figure 2a) all exhibit similar features with broad $\mathrm{D}$ and $\mathrm{G}$ bands, and the $\mathrm{I}_{\mathrm{D}} / \mathrm{I}_{\mathrm{G}}$ ratio showing no significant difference (Figure S5b). 

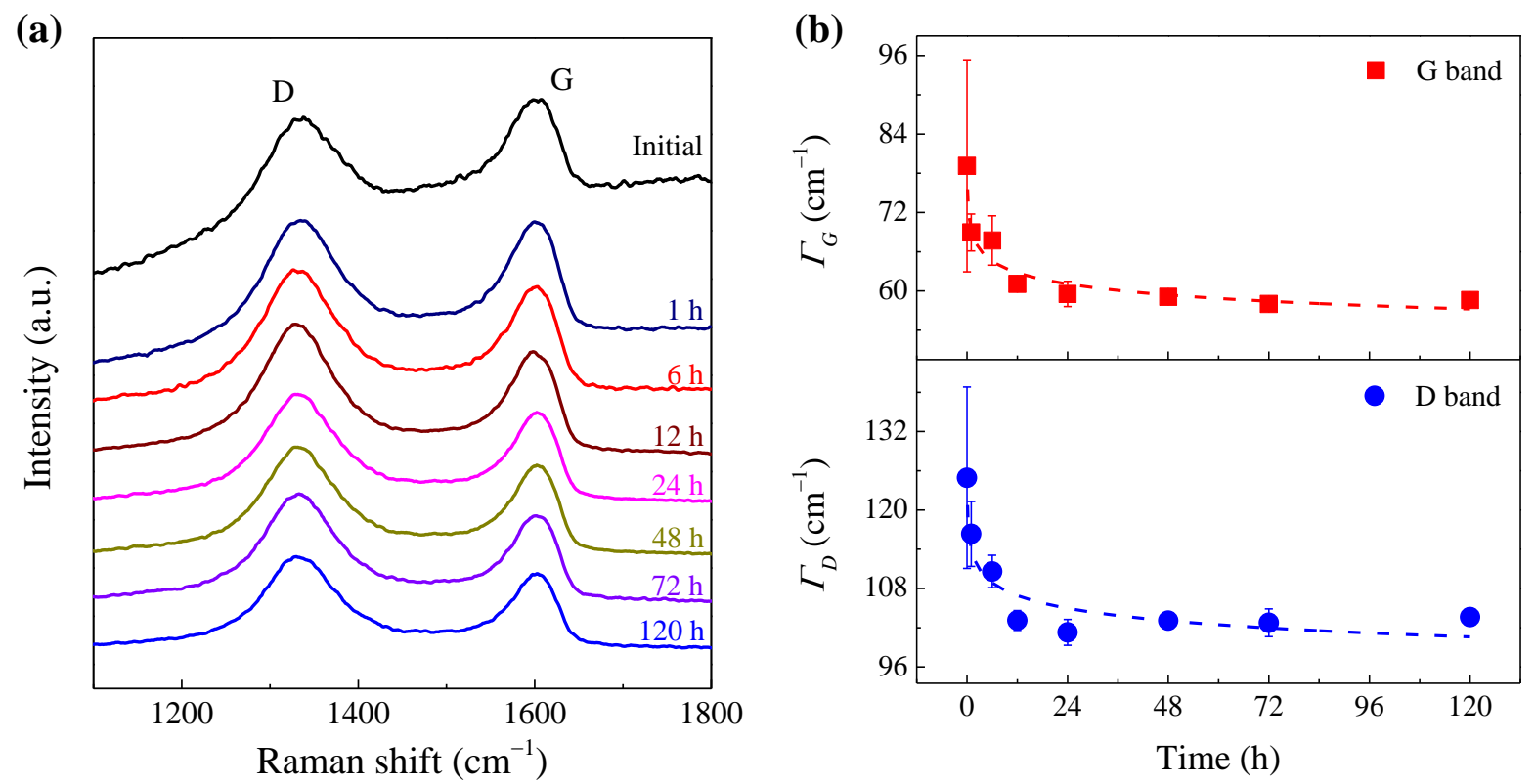

Figure 2. (a) Typical Raman spectra obtained from the GO/BP hybrid film being exposed to $100 \%$ humidity at $25{ }^{\circ} \mathrm{C}$ for various times; (b) Evolution of FWHM of the G and D bands with increasing time of exposure to $100 \%$ humidity.

Nevertheless, by analyzing the fitted results, we found that the average FWHM for the G and $\mathrm{D}$ bands decrease quickly in the first $24 \mathrm{~h}$ of exposure, and then remain stable at $\sim 60 \mathrm{~cm}^{-1}$ for the $\mathrm{G}$ band and $\sim 104 \mathrm{~cm}^{-1}$ for the D band (Figure $2 \mathrm{~b}$ ). The decrease of $\Gamma_{G}$ in the first $24 \mathrm{~h}$ could be related to the reduction of GO according to the previous investigation. ${ }^{33}$ The small change in $\Gamma_{G}$ after $24 \mathrm{~h}$ suggests that the reduction of GO is probably completed within the first $24 \mathrm{~h}$. However, this assumption is in conflict with the XRD results, which indicates the complete reduction of GO requires up to $96 \mathrm{~h}$. Considering the diffusion of water and oxygen molecules starts from the surface of the GO/BP hybrid film, hence the reduction reaction will occurs firstly near the surface. On the other hand, the analyzing depth of Raman spectroscopy is limited by the transmittance of the sample to the laser used, thus RGO with black colour will limit the sensitivity of Raman spectroscopy to the few layers of RGO near surface. Hence, it is reasonable to suppose that the reduction of GO layers located near the surface can 
be finished in the first $24 \mathrm{~h}$, but for the GO in the bulk film, thorough reduction requires up to $96 \mathrm{~h}$ based on the XRD results. For the control samples, representative Raman spectra are displayed in Figure $\mathrm{S} 6$, and the corresponding comparison of $\Gamma_{\mathrm{D}}, \Gamma_{\mathrm{G}}$ and $\mathrm{I}_{\mathrm{D}} / \mathrm{I}_{\mathrm{G}}$ ratio is available in Figure $S 6$ b, $c$ and d, respectively. The results suggest that the $\Gamma_{G}$ values for GO/BP films exposed to humid air and $\mathrm{N}_{2}$ for $72 \mathrm{~h}$ show obvious decrease due to $\mathrm{GO}$ reduction when compared with that in dry air and bulk $\mathrm{H}_{2} \mathrm{O}$. These results are consistent with the XRD characterization shown in Figure 1.

FT-IR spectra further confirmed the reduction of GO and the formation of phosphorus containing acids. As shown in Figure 3a, the characteristic peaks of oxygen functionalities appear in the spectrum of the GO/BP hybrid film, including: the stretching vibration peak of $\mathrm{C}=\mathrm{O}$ at $1735 \mathrm{~cm}^{-1}$, the $\mathrm{O}-\mathrm{H}$ peak at $1409 \mathrm{~cm}^{-1}$ and the $\mathrm{C}-\mathrm{O}$ epoxide peak at $1233 \mathrm{~cm}^{-1} \cdot{ }^{34} \mathrm{In}$ contrast, the $\mathrm{RGO} / \mathrm{H}_{x} \mathrm{PO}_{y}$ film exhibits a clear peak at $1580 \mathrm{~cm}^{-1}$, corresponding to the $\mathrm{C}=\mathrm{C}$ stretching band, ${ }^{34}$ and a weak $\mathrm{C}=\mathrm{O}$ peak at $1735 \mathrm{~cm}^{-1}$, again suggesting the removal of most of the oxygen functionalities. The presence of phosphorus acids is seen with the peak located at $1227 \mathrm{~cm}^{-1},(\mathrm{P}=\mathrm{O}$ stretching $)$ and the peak at $1038 \mathrm{~cm}^{-1}$ (P-OH bending $) .{ }^{35}$ For comparison, the FT-IR spectra of control samples (stored in various environments and conditions for $72 \mathrm{~h}$ ) were also recorded (see Figure S7). Reduction of GO only occurred with the GO/BP film stored in the humid $\mathrm{N}_{2}$, and no obvious change in the characteristics of FT-IR spectra recorded from the GO/BP films stored in dry air, dry $\mathrm{N}_{2}$ and vacuum. The FT-IR results are consistent with those of the XRD and Raman characterization. 

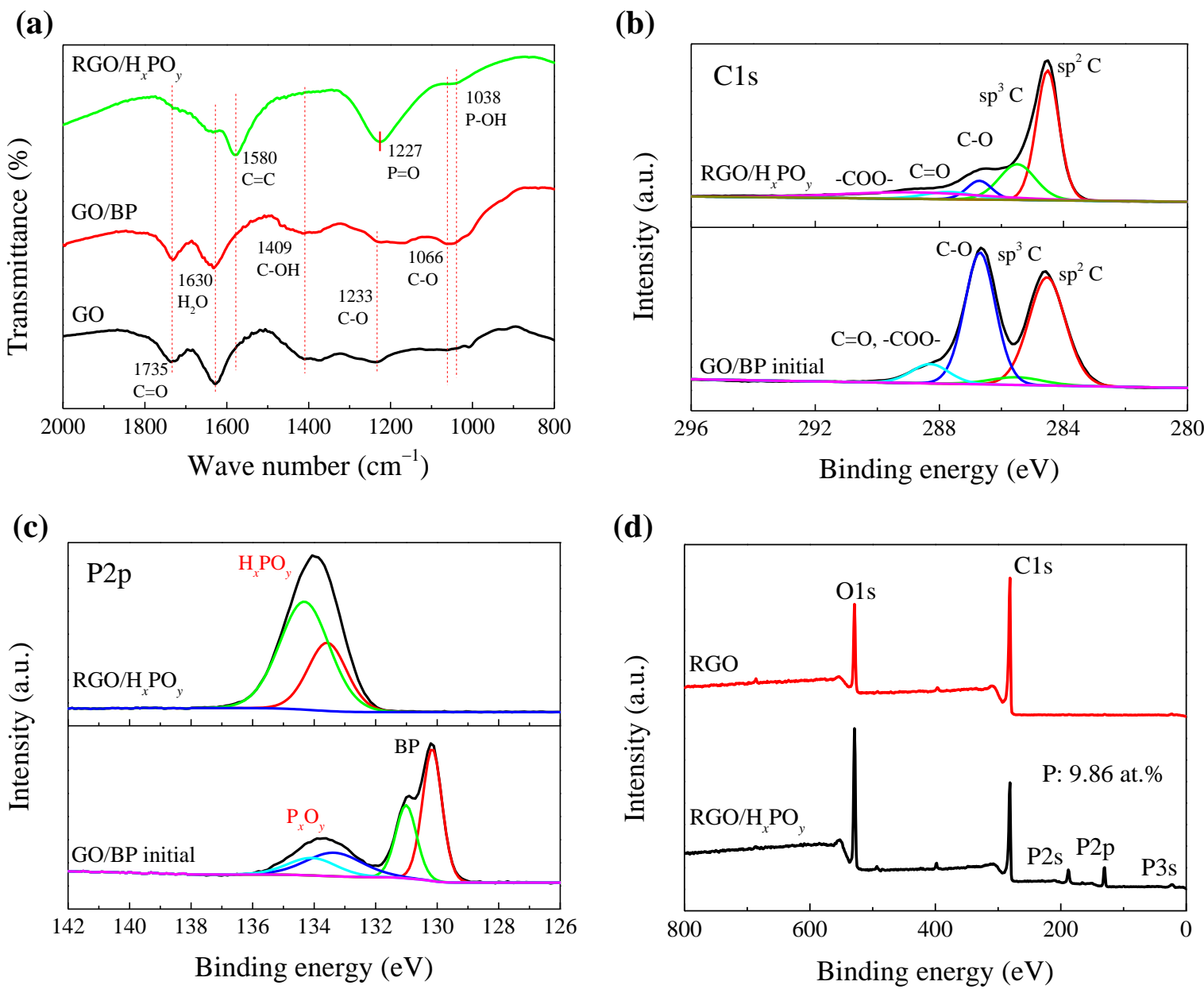

Figure 3. (a) XPS $\mathrm{C} 1 \mathrm{~s}$ spectra of $\mathrm{GO}$ and $\mathrm{RGO} / \mathrm{H}_{x} \mathrm{PO}_{y}$ film. (b) XPS P2p spectrum of $\mathrm{RGO} / \mathrm{H}_{x} \mathrm{PO}_{y}$ film. (c) XPS survey spectra of $\mathrm{RGO} / \mathrm{H}_{x} \mathrm{PO}_{y}$ and $\mathrm{RGO}$ (prepared by washing $\mathrm{RGO} / \mathrm{H}_{x} \mathrm{PO}_{y}$ film with water to remove $\mathrm{H}_{x} \mathrm{PO}_{y}$ acids. (d) FT-IR spectra of GO, initial GO/BP hybrid film, and $\mathrm{RGO} / \mathrm{H}_{x} \mathrm{PO}_{y}$ films.

The structural changes in the GO/BP hybrid film exposed to humid air were further investigated using XPS. Figure 3a compares the C1s spectra from the initial GO/BP hybrid film and the $\mathrm{RGO} / \mathrm{H}_{x} \mathrm{PO}_{y}$ film. This shows that the majority of the oxygen functionalities on the GO sheets have been reduced. Figure $3 b$ compares the high-resolution P2p spectra of the initial GO/BP hybrid film and the $\mathrm{RGO} / \mathrm{H}_{x} \mathrm{PO}_{y}$ film formed after exposure to humidity. The majority of the phosphorus in the initial GO/BP hybrid film exists as pristine BP, confirmed by the $\mathrm{P} 2 \mathrm{p}^{1 / 2}$ component at $131.0 \mathrm{eV}$ and $\mathrm{P} 2 \mathrm{p}^{3 / 2}$ component at $130.1 \mathrm{eV}$. Components 
corresponding to the oxidized phosphorus $\left(\mathrm{PO}_{x}\right)$ also exist, probably due to the partial degradation that occurs during the solution exfoliation and the vacuum filtration process. ${ }^{17,36}$ After being exposed to $100 \%$ humidity for $120 \mathrm{~h}$, the BP degraded totally and a single peak related to oxidized phosphorus is present. Since phosphorus oxides tend to hydrolyze in humid atmospheres, the most likely state of these phosphorus oxides is liquid acids $\left(\mathrm{H}_{x} \mathrm{PO}_{y}\right)$. An XPS survey spectrum of the $\mathrm{RGO} / \mathrm{H}_{x} \mathrm{PO}_{y}$ film (Figure 3c) suggests that the film contains 9.86 at.\% $\mathrm{P}$. The as-formed $\mathrm{H}_{x} \mathrm{PO}_{y}$ acids can be easily washed away by soaking the $\mathrm{RGO} / \mathrm{H}_{x} \mathrm{PO}_{y}$ film in water overnight, as confirmed by the XPS survey spectrum of the asformed RGO film shown in the supplementary information (Figure S8). The oxygen contents of the $\mathrm{RGO} / \mathrm{H}_{x} \mathrm{PO}_{y}$ and $\mathrm{RGO}$ film are measured as 28.05 at.\% and 16.21 at.\%, respectively, suggesting that nearly half of the oxygen in the $\mathrm{RGO} / \mathrm{H}_{x} \mathrm{PO}_{y}$ film is bound to the phosphorus. These as-formed acids are believed to be trapped between the RGO layers. The structure of the $\mathrm{RGO} / \mathrm{H}_{x} \mathrm{PO}_{y}$ film is similar to that previously reported with other liquid mediated graphene films. ${ }^{11}$ It is proposed that the acid electrolyte within the RGO layers interacts with and prevents the graphene sheets from closely restacking and serves as an electrolyte enhancing the electrochemical performance.

SEM was used to image and characterize the surface morphologies of the initial GO/BP hybrid film (Figure 4a), the as-formed $\mathrm{RGO} / \mathrm{H}_{x} \mathrm{PO}_{y}$ film (Figure 4b), and the washed pure RGO film (Figure 4c). These films show distinct differences; the initial GO/BP hybrid film has a surface with a particulate morphology, due to the presence of BP nano-flakes amongst the larger GO sheets. In contrast, after exposure to humid air, the as-formed $\mathrm{RGO} / \mathrm{H}_{x} \mathrm{PO}_{y}$ film shows a smooth surface, confirming the degradation and elimination of the BP flakes to form a liquid acid electrolyte. Note that the $\mathrm{RGO} / \mathrm{H}_{x} \mathrm{PO}_{y}$ film was vacuum treated at $\sim 13$ mbar overnight to remove the volatile water, leaving nonvolatile concentrated $\mathrm{H}_{x} \mathrm{PO}_{y}$ liquid acid 
trapped between the graphene layers inside the film. The surface of the washed RGO film shows a wrinkled morphology typical of graphene films, which is distinct from the $\mathrm{RGO} / \mathrm{H}_{x} \mathrm{PO}_{y}$ film. The reason for the appearance of micro-wrinkles is related to the complete removal of the nonvolatile liquid acids by washing. After washing, the liquid acids are exchanged by water, and the capillary force generated during the subsequent vacuum evaporation of water and the restacking of the RGO sheets generates the micro-wrinkles. ${ }^{10}$ Mass ratios of $\mathrm{C}, \mathrm{O}$ and $\mathrm{P}$ elements present in the films were determined by EDX mapping (Supporting Information Figure S9) with the mass ratio of $\mathrm{P}$ measured as 10.2 wt.\% in the $\mathrm{RGO} / \mathrm{H}_{x} \mathrm{PO}_{y}$ film, but only 0.4 wt.\% $\mathrm{P}$ in the washed pure RGO film, which is consistent with the XPS results.

SEM cross sections and the corresponding EDX composition maps of the RGO/ $\mathrm{H}_{x} \mathrm{PO}_{y}$ film and washed RGO film are shown in Figure $4 \mathrm{~d}$ and e. The thickness of the as-formed $\mathrm{RGO} / \mathrm{H}_{x} \mathrm{PO}_{y}$ film is around $1.5 \mu \mathrm{m}$, and the phosphorus is homogeneously distributed throughout the film. Once the as-formed $\mathrm{H}_{x} \mathrm{PO}_{y}$ acids have been washed away, the washed pure RGO film shows a reduced thickness of about $1 \mu \mathrm{m}$ (Figure 4e), and a much weaker phosphorus signal was detected by EDX. The hydrophilicity of the as-formed $\mathrm{RGO} / \mathrm{H}_{x} \mathrm{PO}_{y}$ film and the washed pure RGO film was determined by measuring the water contact angle. As shown in Figure $4 \mathrm{f}$ and $\mathrm{g}$, the water contact angle for $\mathrm{RGO} / \mathrm{H}_{x} \mathrm{PO}_{y}$ film and the washed RGO film is $65.6^{\circ}$ and $84.6^{\circ}$, respectively, suggesting better hydrophilicity of the $\mathrm{RGO} / \mathrm{H}_{x} \mathrm{PO}_{y}$ film due to the existence of water miscible $\mathrm{H}_{x} \mathrm{PO}_{y}$ acids. 

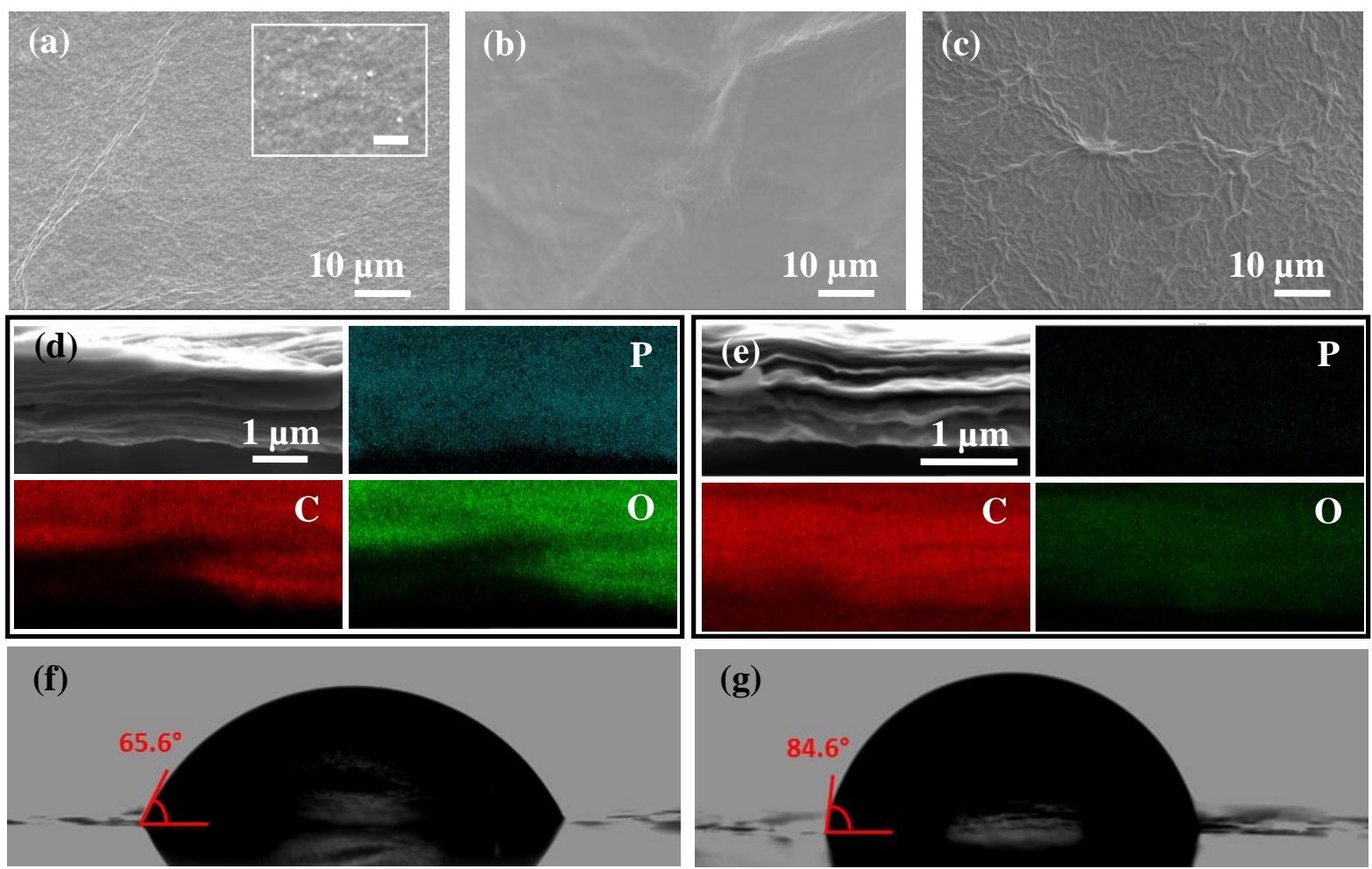

Figure 4. SEM surface morphology of (a) initial GO/BP hybrid film (scale bar in the inset: 2 $\mu \mathrm{m}$ ), (b) RGO/H $\mathrm{H}_{x} \mathrm{PO}_{y}$ film and (c) washed pure RGO film. SEM cross-section morphologies of (d) $\mathrm{RGO} / \mathrm{H}_{x} \mathrm{PO}_{y}$ film and (e) washed RGO film, as well as the corresponding EDS mapping of $\mathrm{P}, \mathrm{C}$ and $\mathrm{O}$ elements. Water contact angels for (f) $\mathrm{RGO} / \mathrm{H}_{x} \mathrm{PO}_{y}$ and (g) washed RGO films

Based on these results, we hypothesize a possible reaction mechanism for the transformation of the GO/BP hybrid film, in which $\mathrm{BP}$ is degraded via reaction with $\mathrm{H}_{2} \mathrm{O}$ and $\mathrm{O}_{2}$, these degradation products subsequently reduce the GO to form conductive RGO. The FT-IR data (Supporting Information Figure S10) shows the degradation products of the BP has similar peaks to those found with $\mathrm{H}_{3} \mathrm{PO}_{2}, \mathrm{H}_{3} \mathrm{PO}_{3}$, and $\mathrm{H}_{3} \mathrm{PO}_{4}$ but is not exactly the same as any of them, indicating that the degradation products are likely to be a mixure of phosphorus oxyacids, which is consistent with previous findings. ${ }^{22,25}$ The XRD spectra obtained from GO films immersed in $\mathrm{H}_{3} \mathrm{PO}_{2}, \mathrm{H}_{3} \mathrm{PO}_{3}$, and $\mathrm{H}_{3} \mathrm{PO}_{4}$ are compared in Figure $\mathrm{S} 11$. The peak corresponding to GO disappears and an RGO peak appears for the film immersed in $\mathrm{H}_{3} \mathrm{PO}_{2}$, 
while the GO films immersed in $\mathrm{H}_{3} \mathrm{PO}_{3}$ and $\mathrm{H}_{3} \mathrm{PO}_{4}$ show no noticable changes to their XRD spectra. This obersvation confirms that only $\mathrm{H}_{3} \mathrm{PO}_{2}$ in the $\mathrm{H}_{x} \mathrm{PO}_{y}$ reaction product from the interaction of BP with humid atmospheres is capable of reducing GO to RGO.

Hence, we propose that the degradation of $\mathrm{BP}$ results in the formation of $\mathrm{H}_{3} \mathrm{PO}_{2}$ by:

$4 \mathrm{P}+\mathrm{O}_{2}+6 \mathrm{H}_{2} \mathrm{O} \rightarrow 4 \mathrm{H}_{3} \mathrm{PO}_{2}$

Other oxyacids of phosphorus may also form but onle $\mathrm{H}_{3} \mathrm{PO}_{2}$ can further react with and reduces GO leading to the formation of $\mathrm{H}_{3} \mathrm{PO}_{3}$ or $\mathrm{H}_{3} \mathrm{PO}_{4} .{ }^{27}$ This is indicated schematically in Figure 5 in accordance with previous reports on the reduciton of GO by hydroxylamine and $\mathrm{NaHSO}_{3}{ }^{37-38}$ The nucleophilic attack results in ring opening of the epoxide groups followed by proton transfer, with the elimination of water leading to the formation of an unstable intermediate, which further converts to a conjugated vinyl and phosphorus acid via reaction with water.

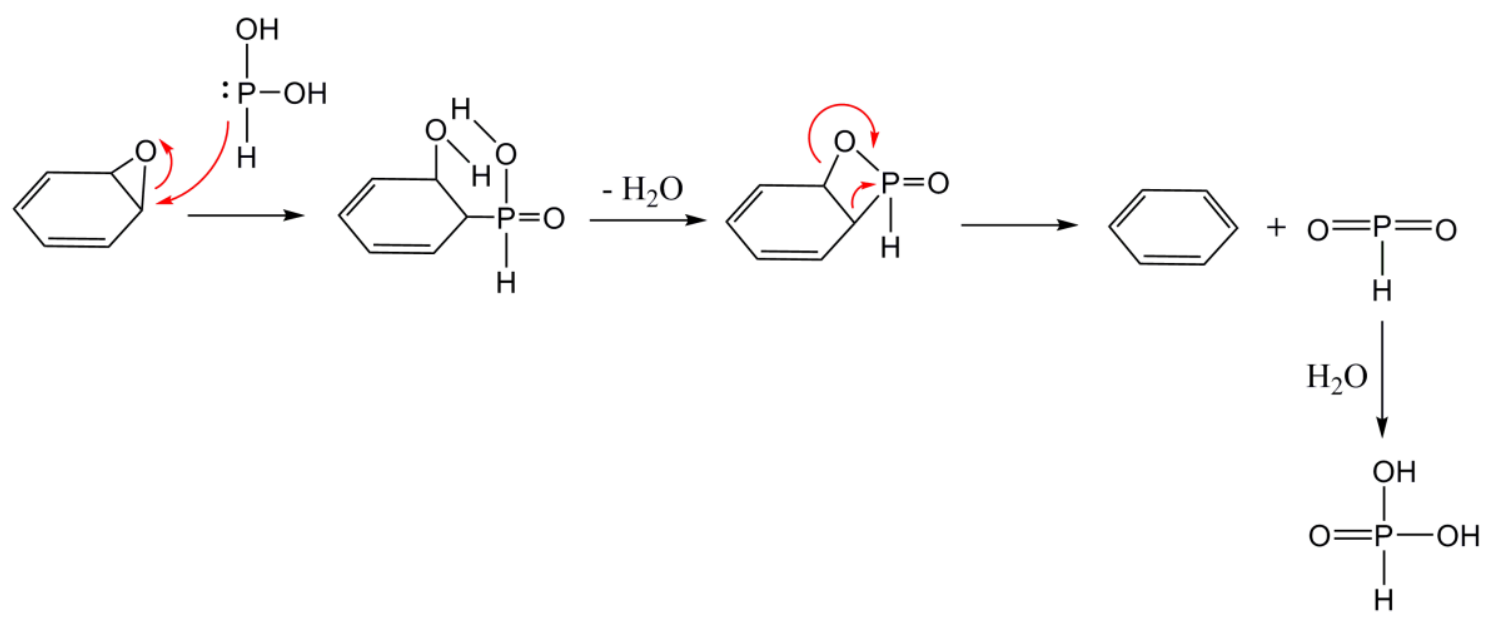

Figure 5. Possible mechanism for the reduction of $\mathrm{GO}$ by $\mathrm{H}_{3} \mathrm{PO}_{2}$. 

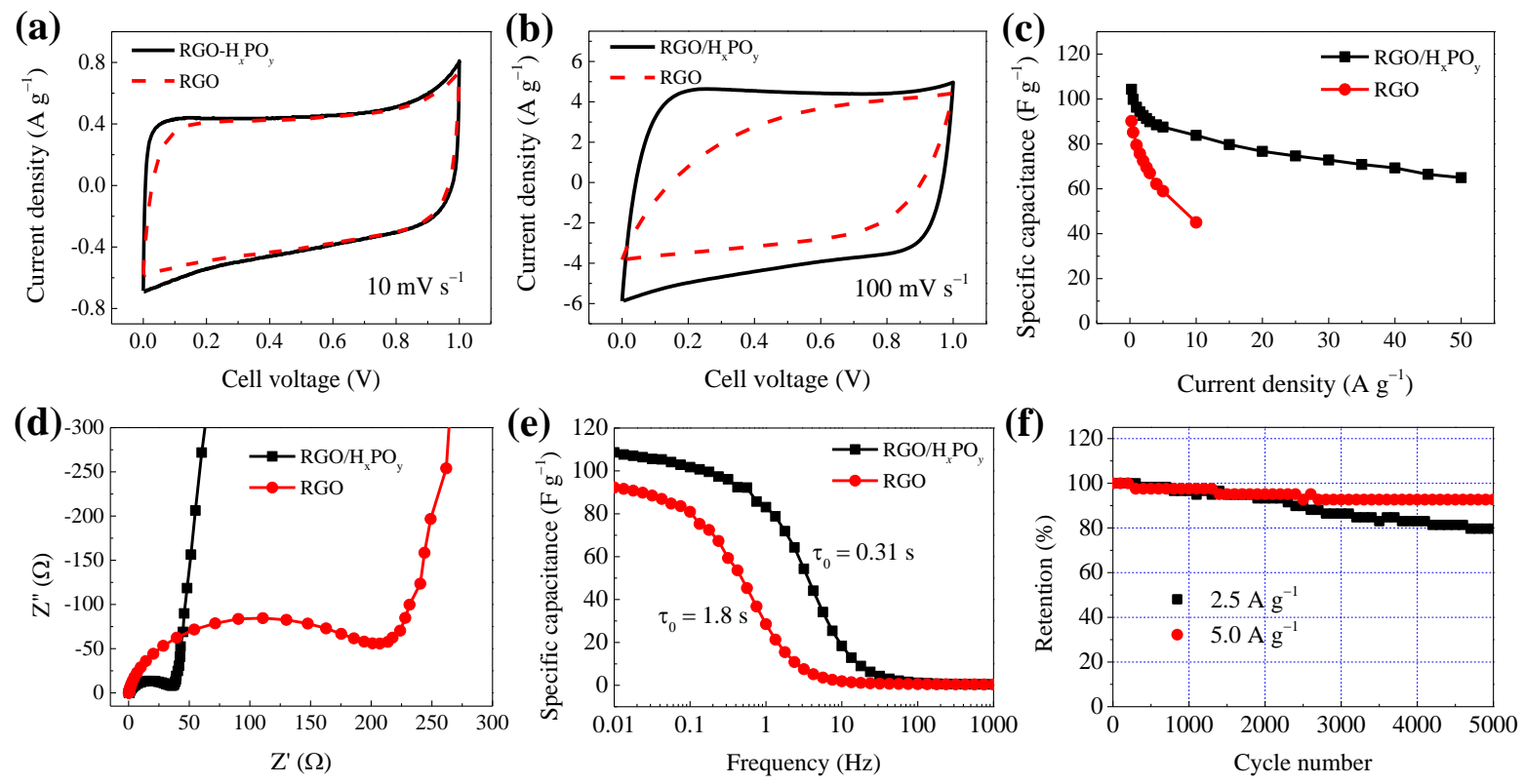

Figure 6. Electrochemical performance of supercapacitor based on $\mathrm{RGO} / \mathrm{H}_{x} \mathrm{PO}_{y}$ film. Comparison of $\mathrm{CV}$ curves of supercapacitors based on $\mathrm{RGO} / \mathrm{H}_{x} \mathrm{PO}_{y}$ and washed $\mathrm{RGO}$ films at (a) 10 and (b) $100 \mathrm{mV} \mathrm{s}^{-1}$. (c) Rate capabilities of supercapacitor based on $\mathrm{RGO} / \mathrm{H}_{x} \mathrm{PO}_{y}$ and washed RGO films. (d) Nyquist plots for the supercapacitors based on $\mathrm{RGO} / \mathrm{H}_{x} \mathrm{PO}_{y}$ and washed RGO films. (e) Evolution of specific capacitances with frequency for the $\mathrm{RGO} / \mathrm{H}_{x} \mathrm{PO}_{y}$ and washed RGO films. (f) Cycling stability of the supercapacitor based on $\mathrm{RGO} / \mathrm{H}_{x} \mathrm{PO}_{y}$ film.

To investigate the applicability of the $\mathrm{RGO} / \mathrm{H}_{x} \mathrm{PO}_{y}$ film, we fabricated a symmetric supercapacitor using two pieces of the $\mathrm{RGO} / \mathrm{H}_{x} \mathrm{PO}_{y}$ film as electrodes and $1 \mathrm{M} \mathrm{H}_{3} \mathrm{PO}_{4}$ aqueous solution as the electrolyte. For comparison, a supercapacitor based on a washed pure RGO film was also fabricated. Figure $6 a$ and $b$ compare the cyclic voltammetry (CV) curves of the $\mathrm{RGO} / \mathrm{H}_{x} \mathrm{PO}_{y}$ and RGO supercapacitors at scan rates of 10 and $100 \mathrm{mV} \mathrm{s} \mathrm{s}^{-1}$, respectively. At the slow scan rate of $10 \mathrm{mV} \mathrm{s}^{-1}$, both the $\mathrm{CV}$ curves of $\mathrm{RGO} / \mathrm{H}_{x} \mathrm{PO}_{y}$ and RGO supercapacitors show a good rectangular shape, indicating that the ion transport inside the graphene film is not inhibited. However, at a higher scan rate of $100 \mathrm{mV} \mathrm{s}^{-1}$, the CV 
curve of the hybrid $\mathrm{RGO} / \mathrm{H}_{x} \mathrm{PO}_{y}$ supercapacitor still maintains the desired rectangular characteristic while that of the RGO supercapacitor deteriorates markedly from the ideal. This phenomenon suggests a sluggish transport of electrolyte ions in the densely restacked RGO film, while in the $\mathrm{RGO} / \mathrm{H}_{x} \mathrm{PO}_{y}$ film, the channels for ion diffusion are preserved by the presence of $\mathrm{H}_{x} \mathrm{PO}_{y}$ acids, leading to an excellent rate capability. A similar behavior and mechanism for enhanced ionic conductivity has been reported by Yang et al. who presented similar electrode behavior with RGO electrodes produced by the reduction of GO by N2H4 and stabilized by colloidal dispersion. ${ }^{10,11}$ Detailed comparison of the $\mathrm{CV}$ curves at various scan rates ranging from 20 to $500 \mathrm{mV} \mathrm{s}^{-1}$ is available in the supplementary information (Supporting Information Figure S12). The rectangular characteristics of the CV curves for the $\mathrm{RGO} / \mathrm{H}_{x} \mathrm{PO}_{y}$ film at high scan rates are approaching that of a liquid electrolyte-mediated graphene film. ${ }^{11}$

Galvanostatic charge-discharge experiments were used to further evaluate the rate performance of the $\mathrm{RGO} / \mathrm{H}_{x} \mathrm{PO}_{y}$ supercapacitor (Supporting information Figure S13). Figure 6c shows that the $\mathrm{RGO} / \mathrm{H}_{x} \mathrm{PO}_{y}$ film exhibits higher specific capacitance at all discharging rates compared with the RGO film, especially at large current densities. At a small discharge current density of $0.25 \mathrm{~A} \mathrm{~g}^{-1}$, the $\mathrm{RGO} / \mathrm{H}_{x} \mathrm{PO}_{y}$ film had a specific capacitance of $104.4 \mathrm{~F} \mathrm{~g}^{-1}$, higher than that of the RGO film $\left(90.1 \mathrm{~F} \mathrm{~g}^{-1}\right)$. The higher specific capacitance of $\mathrm{RGO} / \mathrm{H}_{x} \mathrm{PO}_{y}$ film is believed to be due to the $\mathrm{H}_{x} \mathrm{PO}_{y}$ acids trapped between the graphene layers, which prevent the graphene from restacking through colloidal stabilization mechanisms. Moreover, the $\mathrm{RGO} / \mathrm{H}_{x} \mathrm{PO}_{y}$ film maintains a high specific capacitance $\left(65.0 \mathrm{~F} \mathrm{~g}^{-1}\right)$ even at a large current density of $50 \mathrm{~A} \mathrm{~g}^{-1}$, while the specific capacitance of the RGO films drops rapidly with a specific capacitance of $45 \mathrm{~F} \mathrm{~g}^{-1}$ at a current density of $10 \mathrm{~A} \mathrm{~g}^{-1}$. The specific capacitance of $\mathrm{RGO} / \mathrm{H}_{x} \mathrm{PO}_{y}$ film $\left(104.4 \mathrm{~F} \mathrm{~g}^{-1}\right.$ at $0.25 \mathrm{~A} \mathrm{~g}^{-1}$ and $65.0 \mathrm{~F} \mathrm{~g}^{-1}$ at $\left.50 \mathrm{~A} \mathrm{~g}^{-1}\right)$ is better than that of 
the previously reported macro-porous graphene film $\left(58.1 \mathrm{~F}^{-1}\right.$ at $\left.1 \mathrm{~A} \mathrm{~g}^{-1}\right){ }^{39}$ electrochemically exfoliated graphene $\left(56.6 \mathrm{~F} \mathrm{~g}^{-1}\right.$ at $\left.1 \mathrm{mV} \mathrm{s}^{-1}\right),{ }^{40} \mathrm{GO}$ reduced by $\mathrm{Zn}$ powder $\left(68 \mathrm{~F} \mathrm{~g}^{-1}\right.$ at $\left.5 \mathrm{~A} \mathrm{~g}^{-1}\right),{ }^{41}$ electrophoretic deposited graphene on carbon cloth $\left(70 \mathrm{~F} \mathrm{~g}^{-1}\right.$ at $1 \mathrm{~A}$ $\left.\mathrm{g}^{-1}\right)^{42}$ and $\mathrm{RGO} /$ carbon black hybrid gel film $\left(95.7 \mathrm{~F} \mathrm{~g}^{-1}\right.$ at $\left.5 \mathrm{mV} \mathrm{s}^{-1}\right){ }^{13}$ The specific capacitances of $\mathrm{RGO} / \mathrm{H}_{x} \mathrm{PO}_{y}$ film are also comparable with the graphene-cellulose paper (120 $\mathrm{F} \mathrm{g} \mathrm{g}^{-1}$ at $\left.1 \mathrm{mV} \mathrm{s}^{-1}\right),{ }^{43}$ pristine graphene aerogel $\left(123 \mathrm{~F} \mathrm{~g}^{-1}\right.$ at $\left.1 \mathrm{~A} \mathrm{~g} \mathrm{~g}^{-1}\right),{ }^{44}$ and the liquid electrolyte mediated graphene film $\left(100 \mathrm{~F} \mathrm{~g}^{-1}\right.$ at $\left.100 \mathrm{~A} \mathrm{~g}^{-1}\right){ }^{11}$ See Table S2 in the supplementary information for a more detailed comparison of this data.

Electrochemical impedance spectroscopy (EIS) was also performed to investigate the role of the as-transformed $\mathrm{H}_{x} \mathrm{PO}_{y}$ acid electrolyte. As shown in Figure 6d, the internal resistance of the RGO supercapacitor, determined by the high frequency intercept along the $x$-axis, is much larger than that of the $\mathrm{RGO} / \mathrm{H}_{x} \mathrm{PO}_{y}$ supercapacitor. Figure 6e shows plots of specific capacitance versus frequency for the $\mathrm{RGO} / \mathrm{H}_{x} \mathrm{PO}_{y}$ and $\mathrm{RGO}$ supercapacitors. At low frequency, the specific capacitance of the $\mathrm{RGO} / \mathrm{H}_{x} \mathrm{PO}_{y}$ supercapacitor is larger than that made with RGO, which is consistent with the galvanostatic discharging results. Moreover, the relaxation time of the supercapacitor, determined by frequency at half of the initial capacitance, is $0.31 \mathrm{~s}$ for the $\mathrm{RGO} / \mathrm{H}_{x} \mathrm{PO}_{y}$ supercapacitor, which is much shorter than that for the RGO (1.8 s), corresponding to an enhanced rate capability. Ragone plots (energy density versus power density) of the supercapacitors based on the $\mathrm{RGO} / \mathrm{H}_{x} \mathrm{PO}_{y}$ film and the washed RGO film are available in Figure $\mathrm{S} 14$ in the supporting information. The $\mathrm{RGO} / \mathrm{H}_{x} \mathrm{PO} y$ film is able to maintain an energy density of $2.2 \mathrm{Wh} \mathrm{kg}^{-1}$ at a high power density of $48 \mathrm{~kW} \mathrm{~kg}^{-1}$. The relative low energy density of $\mathrm{RGO} / \mathrm{H}_{x} \mathrm{PO}_{y}$ film when compared to the commercial supercapacitor based on activated carbon $\left(\sim 5 \mathrm{Wh} \mathrm{kg}^{-1}\right)$ is due to the use of an aqueous electrolyte, which limits the cell voltage to $1.0 \mathrm{~V}$. Finally, the cycling stability of the 
$\mathrm{RGO} / \mathrm{H}_{x} \mathrm{PO}_{y}$ film was investigated by galvanostatic charging-discharging at current densities of 2.5 and $5 \mathrm{~A} \mathrm{~g}^{-1}$. As shown in Figure 6f, the supercapacitor based on $\mathrm{RGO} / \mathrm{H}_{x} \mathrm{PO}_{y}$ film is able to be charged and discharged for 5000 cycles with retention of $92.7 \%$ at $5 \mathrm{~A} \mathrm{~g}^{-1}$ and $79.6 \%$ at $2.5 \mathrm{~A} \mathrm{~g} \mathrm{~g}^{-1}$. We note that similar highly stable supercapacitor performance after repeated cycling has been reported by Yang et al using colloidally stabilized RGO sheets. ${ }^{10,11}$ In our case we have proposed that the $\mathrm{H}_{x} \mathrm{PO}_{y}$ acids present in the electrolyte act as colloidal stabilisers, preventing the restacking of RGO sheets, thus the mechanisms for the long term stability of the electrodes are probably similar to those occurring in Yang et al's experiments. Further study is needed to determine the mechanisms for the cycling stability of the electrodes and performance after longer times.

We further investigated the effect of GO to BP mass ratio in the initial hybrid film on the electrochemical performance of the as-formed $\mathrm{RGO} / \mathrm{H}_{x} \mathrm{PO}_{y}$ film. As shown in Figure $7 \mathrm{a}$ and $\mathrm{b}$, by increasing the content of $\mathrm{BP}$ in the initial hybrid film from GO:BP $=2: 1$ to GO:BP $=$ 1:2, the $\mathrm{CV}$ curves of the as-derived $\mathrm{RGO} / \mathrm{H}_{x} \mathrm{PO}_{y}$ film at both 10 and $100 \mathrm{mV} \mathrm{s}^{-1}$ show slightly larger enclosed area. According to the rate capability (Figure 7c), the specific capacitance of the $\mathrm{RGO} / \mathrm{H}_{x} \mathrm{PO}_{y}$ film with an initial GO:BP ratio of 1:2 shows slightly higher specific capacitance at all current density range than that of the film with an initial GO :BP ratio of $2: 1$. In addition, the $\mathrm{RGO} / \mathrm{H}_{x} \mathrm{PO}_{y}$ film with an initial GO:BP ratio of 1:2 shows smaller internal resistance in the Nyquist plots (Figure 7d) than that of the film with an initial GO : BP ratio of 2:1. The enhanced performance is probably due to more efficient reduction of $\mathrm{GO}$ as the amount of reductive $\mathrm{H}_{3} \mathrm{PO}_{2}$ from the degradation of $\mathrm{BP}$ increases, this has been confirmed by the XPS characterization as the oxygen content of the as-derived RGO film decreased slightly from 16.21 at.\% $(\mathrm{GO}: \mathrm{BP}=2: 1)$ to 13.58 at. $\%(\mathrm{GO}: \mathrm{BP}=1: 2)$, see Figure S15 for the XPS survey and C1s spectra. In addition, the amount of acid electrolyte $\mathrm{H}_{\mathrm{x}} \mathrm{PO}_{\mathrm{y}}$ 
from BP degradation would also increase with higher content of BP in the initial hybrid film, thus prevent more RGO layers from compact restacking and allow fast ion movement inside the film.

(a)

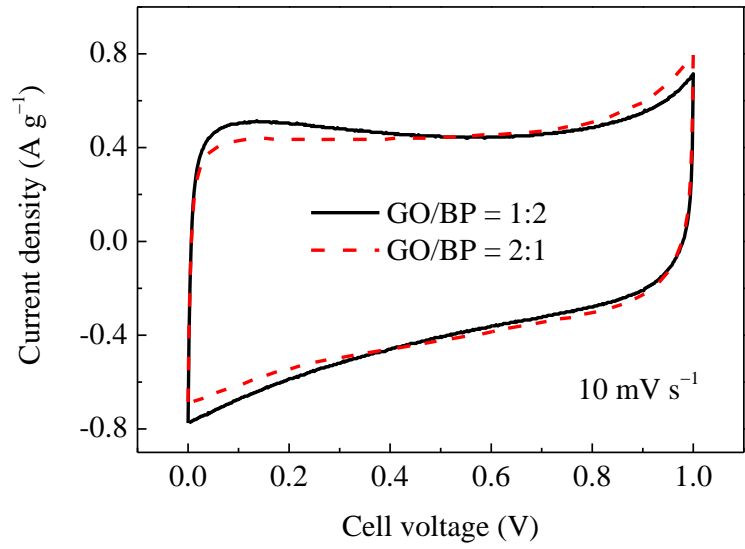

(c)

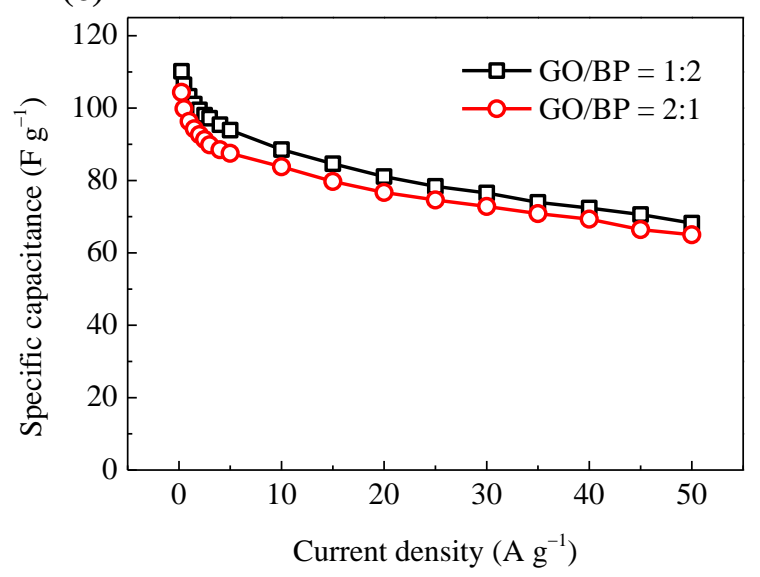

(b)

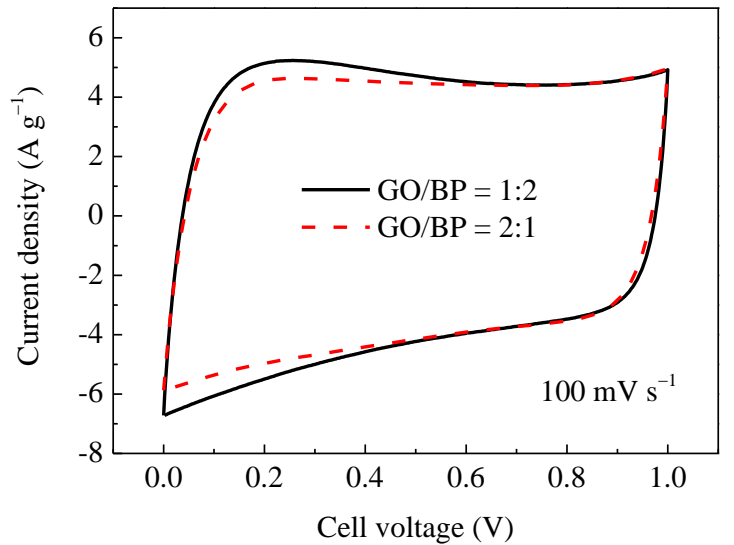

(d)

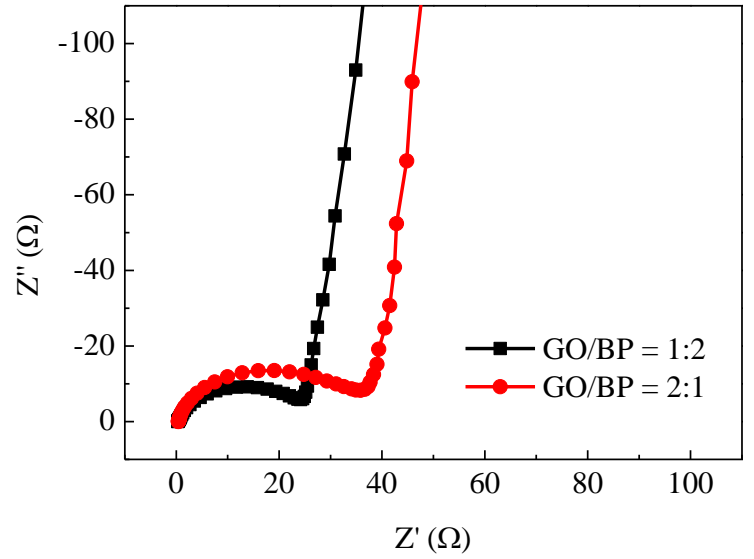

Figure 7. Electrochemical performances of supercapacitors based on $\mathrm{RGO} / \mathrm{H}_{x} \mathrm{PO}$ films derived from GO/BP films with different GO : BP mass ratio of 1:2 and 2:1. (a) and (b) comparison of $\mathrm{CV}$ curves at scan rates of 10 and $100 \mathrm{mV} \mathrm{s}^{-1}$, respectively. (c) Evolution of specific capacitance with discharge current density. (d) Nyquist plots.

However, the enhancement in the electrochemical performance is not significant, as the specific capacitance just increased from 104 to $110 \mathrm{~F} \mathrm{~g}^{-1}$ by change the initial GO : BP ratio from 2:1 to 1:2. Taking the high cost of BP raw material and the low yield of few layers BP 
by liquid phase exfoliation into consideration, the benefit from adding more BP into the initial GO/BP film is obviously not cost effective.

\section{CONCLUSION}

In summary, electrode materials with enhanced performance can be obtained from liquid phase exfoliated few-layer BP sandwiched between GO sheets after exposure to humid air. The oxidation of the BP leads to phosphorus acids $\left(\mathrm{H}_{x} \mathrm{PO}_{y}\right)$ which reduce the GO to RGO and also act as a liquid electrolyte to prevent the compact restacking of the RGO sheets. The asformed $\mathrm{RGO} / \mathrm{H}_{x} \mathrm{PO}_{y}$ film shows a high electrical conductivity of $837 \pm 109 \mathrm{~S} \mathrm{~m}^{-1}$. We propose that the presence of liquid $\mathrm{H}_{x} \mathrm{PO}_{y}$ acids trapped between the RGO layers preserves inhibited channels for ion diffusion, leading to enhanced electrochemical performance. A supercapacitor based on the $\mathrm{RGO} / \mathrm{H}_{x} \mathrm{PO}_{y}$ film exhibits a specific capacitance of $104.4 \mathrm{~F} \mathrm{~g}^{-1}$ at $0.25 \mathrm{~A} \mathrm{~g} \mathrm{~g}^{-1}$ and superior rate capability with $62.3 \%\left(65.0 \mathrm{~F} \mathrm{~g}^{-1}\right)$ of the initial capacitance retained at a high current density of $50 \mathrm{~A} \mathrm{~g}^{-1}$, together with good cycling stability. The strategy of exploiting solid-liquid transformations to generate structural modification of film electrodes could lead to the development of high performance energy storage systems.

\section{ASSOCIATED CONTENT}

Supporting information

The supporting information is available free of charge on the ACS Publications website. Experimental details; flake distribution of BP and GO flakes; AFM images and height profile of GO sheets; XRD pattern of BP crystal; XPS P2p core-level spectra of $\mathrm{RGO} / \mathrm{H}_{x} \mathrm{PO}_{y}$ and RGO film; EDX weight ratio of carbon $(\mathrm{C})$, oxygen $(\mathrm{O})$ and phosphorus $(\mathrm{P})$ elements; Compare of FT-IR spectra of BP degradated products with that of $\mathrm{H}_{3} \mathrm{PO}_{2}, \mathrm{H}_{3} \mathrm{PO}_{3}$, and $\mathrm{H}_{3} \mathrm{PO}_{4}$; 
XRD pattern of GO and GO films reduced by $\mathrm{H}_{3} \mathrm{PO}_{2}, \mathrm{H}_{3} \mathrm{PO}_{3}$ and $\mathrm{H}_{3} \mathrm{PO}_{4}$ at $50{ }^{\circ} \mathrm{C}$ for $12 \mathrm{~h}$; $\mathrm{CV}$ curves at various scan rates, galvanostatic charging-discharging curves and Ragone plots of the supercapacitors based on $\mathrm{RGO} / \mathrm{H}_{x} \mathrm{PO}_{y}$ and $\mathrm{RGO}$ films, respectively; summay of $\mathrm{BP}$ degradation and GO reduciton under different enviroments and conditions; comparison of specific capacitance and cycling stabilty of various reported graphene based electrodes.

\section{AUTHOR INFORMATION}

\section{Corresponding Authors}

*pei.he@manchester.ac.uk

*brian.derby@manchester.ac.uk

\section{Author contributions}

The manuscript was written through contributions of all authors. All authors have given approval to the final version of the manuscript. ${ }^{\star}$ These authors contributed equally.

\section{Notes}

The authors declare no competing financial interest.

\section{ACKNOWLEDGEMENTS}

The authors are grateful to the Engineering and Physical Sciences Research Council (EPSRC), grant reference EP/N010345/1, EP/L012022/1, EP/K016954/1 and EP/L020742/1 for supporting this work.

\section{REFERENCES}


(1) Park, S.; Ruoff, R. S. Chemical methods for the production of graphenes. Nat. Nanotechnol. 2009, 4 (4), 217-24.

(2) Dreyer, D. R.; Park, S.; Bielawski, C. W.; Ruoff, R. S. The chemistry of graphene oxide. Chem. Soc. Rev. 2010, 39 (1), 228-40.

(3) Zhu, Y.; Murali, S.; Cai, W.; Li, X.; Suk, J. W.; Potts, J. R.; Ruoff, R. S. Graphene and graphene oxide: synthesis, properties, and applications. Adv. Mater. 2010, 22 (35), 3906-24.

(4) Chua, C. K.; Pumera, M. Chemical reduction of graphene oxide: a synthetic chemistry viewpoint. Chem. Soc. Rev. 2014, 43 (1), 291-312.

(5) Cao, J.; He, P.; Mohammed, M. A.; Zhao, X.; Young, R. J.; Derby, B.; Kinloch, I. A.; Dryfe, R. A. W. Two-Step Electrochemical Intercalation and Oxidation of Graphite for the Mass Production of Graphene Oxide. J. Am. Chem. Soc. 2017, 139 (48), 17446-17456.

(6) Chen, H.; Müller, M. B.; Gilmore, K. J.; Wallace, G. G.; Li, D. Mechanically Strong, Electrically Conductive, and Biocompatible Graphene Paper. Adv. Mater. 2008, 20 (18), $3557-3561$.

(7) Li, D.; Muller, M. B.; Gilje, S.; Kaner, R. B.; Wallace, G. G. Processable aqueous dispersions of graphene nanosheets. Nat Nanotechnol 2008, 3 (2), 101-5.

(8) Shao, Y.; El-Kady, M. F.; Wang, L. J.; Zhang, Q.; Li, Y.; Wang, H.; Mousavi, M. F.; Kaner, R. B. Graphene-based materials for flexible supercapacitors. Chem. Soc. Rev. 2015, 44 (11), 3639-65.

(9) Wang, X.; Shi, G. Flexible graphene devices related to energy conversion and storage. Energy Environ. Sci. 2015, 8 (3), 790-823.

(10) Yang, X.; Zhu, J.; Qiu, L.; Li, D. Bioinspired effective prevention of restacking in multilayered graphene films: towards the next generation of high-performance supercapacitors. Adv. Mater. 2011, 23 (25), 2833-8. 
(11) Yang, X.; Cheng, C.; Wang, Y.; Qiu, L.; Li, D. Liquid-mediated dense integration of graphene materials for compact capacitive energy storage. Science 2013, 341 (6145), 534-7. (12) Cheng, Y.; Lu, S.; Zhang, H.; Varanasi, C. V.; Liu, J. Synergistic effects from graphene and carbon nanotubes enable flexible and robust electrodes for high-performance supercapacitors. Nano Lett. 2012, 12 (8), 4206-11.

(13) Wang, Y.; Chen, J.; Cao, J.; Liu, Y.; Zhou, Y.; Ouyang, J.-H.; Jia, D. Graphene/carbon black hybrid film for flexible and high rate performance supercapacitor. J. Power Sources 2014, 271, 269-277.

(14) Chen, J.; Wang, Y.; Cao, J.; Liu, Y.; Ouyang, J.-H.; Jia, D.; Zhou, Y. Flexible and solidstate asymmetric supercapacitor based on ternary graphene/MnO2/carbon black hybrid film with high power performance. Electrochim. Acta 2015, 182, 861-870.

(15) Brent, J. R.; Savjani, N.; Lewis, E. A.; Haigh, S. J.; Lewis, D. J.; O'Brien, P. Production of few-layer phosphorene by liquid exfoliation of black phosphorus. Chem. Commun. 2014, $50(87), 13338-41$.

(16) Favron, A.; Gaufres, E.; Fossard, F.; Phaneuf-L'Heureux, A. L.; Tang, N. Y.; Levesque, P. L.; Loiseau, A.; Leonelli, R.; Francoeur, S.; Martel, R. Photooxidation and quantum confinement effects in exfoliated black phosphorus. Nat. Mater. 2015, 14 (8), 826-32.

(17) Hanlon, D.; Backes, C.; Doherty, E.; Cucinotta, C. S.; Berner, N. C.; Boland, C.; Lee, K.; Harvey, A.; Lynch, P.; Gholamvand, Z.; Zhang, S.; Wang, K.; Moynihan, G.; Pokle, A.; Ramasse, Q. M.; McEvoy, N.; Blau, W. J.; Wang, J.; Abellan, G.; Hauke, F.; Hirsch, A.; Sanvito, S.; O'Regan, D. D.; Duesberg, G. S.; Nicolosi, V.; Coleman, J. N. Liquid exfoliation of solvent-stabilized few-layer black phosphorus for applications beyond electronics. Nat. Commun. 2015, 6, 8563.

(18) Del Rio Castillo, A. E.; Pellegrini, V.; Sun, H.; Buha, J.; Dinh, D. A.; Lago, E.; Ansaldo, A.; Capasso, A.; Manna, L.; Bonaccorso, F. Exfoliation of Few-Layer Black Phosphorus in 
Low-Boiling-Point Solvents and Its Application in Li-Ion Batteries. Chem. Mater. 2018, 30 (2), 506-516.

(19) Bat-Erdene, M.; Batmunkh, M.; Shearer, C. J.; Tawfik, S. A.; Ford, M. J.; Yu, L.;

Sibley, A. J.; Slattery, A. D.; Quinton, J. S.; Gibson, C. T.; Shapter, J. G. Efficient and Fast Synthesis of Few-Layer Black Phosphorus via Microwave-Assisted Liquid-Phase Exfoliation. Small Methods 2017, 1 (12), 1700260.

(20) Wood, J. D.; Wells, S. A.; Jariwala, D.; Chen, K. S.; Cho, E.; Sangwan, V. K.; Liu, X. L.; Lauhon, L. J.; Marks, T. J.; Hersam, M. C. Effective Passivation of Exfoliated Black Phosphorus Transistors against Ambient Degradation. Nano Lett 2014, 14 (12), 6964-6970. (21) Joshua, O. I.; Gary, A. S.; Herre, S. J. v. d. Z.; Andres, C.-G. Environmental instability of few-layer black phosphorus. 2D Materials 2015, 2 (1), 011002.

(22) Hanlon, D.; Backes, C.; Doherty, E.; Cucinotta, C. S.; Berner, N. C.; Boland, C.; Lee, K.; Harvey, A.; Lynch, P.; Gholamvand, Z.; Zhang, S.; Wang, K.; Moynihan, G.; Pokle, A.; Ramasse, Q. M.; McEvoy, N.; Blau, W. J.; Wang, J.; Abellan, G.; Hauke, F.; Hirsch, A.; Sanvito, S.; O'Regan, D. D.; Duesberg, G. S.; Nicolosi, V.; Coleman, J. N. Liquid exfoliation of solvent-stabilized few-layer black phosphorus for applications beyond electronics. Nat Commun 2015, 6, 8563.

(23) Brent, J. R.; Ganguli, A. K.; Kumar, V.; Lewis, D. J.; McNaughter, P. D.; O'Brien, P.; Sabherwal, P.; Tedstone, A. A. On the stability of surfactant-stabilised few-layer black phosphorus in aqueous media. RSC Adv. 2016, 6 (90), 86955-86958.

(24) Huang, Y.; Qiao, J.; He, K.; Bliznakov, S.; Sutter, E.; Chen, X.; Luo, D.; Meng, F.; Su, D.; Decker, J.; Ji, W.; Ruoff, R. S.; Sutter, P. Interaction of Black Phosphorus with Oxygen and Water. Chem. Mater. 2016, 28 (22), 8330-8339. 
(25) Wang, Y.; Yang, B.; Wan, B.; Xi, X.; Zeng, Z.; Liu, E.; Wu, G.; Liu, Z.; Wang, W. Degradation of black phosphorus: a real-time31P NMR study. 2D Materials 2016, 3 (3), 035025 .

(26) Zhou, Q.; Chen, Q.; Tong, Y.; Wang, J. Light-Induced Ambient Degradation of FewLayer Black Phosphorus: Mechanism and Protection. Angew. Chem. Int. Edit. 2016, 55 (38), $11437-41$

(27) Wang, X.; Xing, W.; Yu, B.; Feng, X.; Song, L.; Hu, Y. A facile and cost-effective approach to the reduction of exfoliated graphite oxide using sodium hypophosphite under acidic conditions. J. Mater. Chem. C 2013, 1 (4), 690-694.

(28) Pei, H.; Brian, D. Inkjet printing ultra-large graphene oxide flakes. 2D Materials 2017, 4 (2), 021021.

(29) Cao, J. Y.; Wang, Y. M.; Chen, J. C.; Li, X. H.; Walsh, F. C.; Ouyang, J. H.; Jia, D. C.; Zhou, Y. Three-dimensional graphene oxide/polypyrrole composite electrodes fabricated by one-step electrodeposition for high performance supercapacitors. J. Mater. Chem. A 2015, 3 (27), 14445-14457.

(30) Stoller, M. D.; Ruoff, R. S. Best practice methods for determining an electrode material's performance for ultracapacitors. Energy Environ. Sci. 2010, 3 (9), 1294.

(31) Abraham, J.; Vasu, K. S.; Williams, C. D.; Gopinadhan, K.; Su, Y.; Cherian, C. T.; Dix, J.; Prestat, E.; Haigh, S. J.; Grigorieva, I. V.; Carbone, P.; Geim, A. K.; Nair, R. R. Tunable sieving of ions using graphene oxide membranes. Nat Nanotechnol 2017, 12 (6), 546-550. (32) Eigler, S. Controlled Chemistry Approach to the Oxo-Functionalization of Graphene. Chem.-Eur. J. 2016, 22 (21), 7012-27.

(33) Hong, J. Y.; Kong, J.; Kim, S. H. Spatially controlled graphitization of reduced graphene oxide films via a green mechanical approach. Small 2014, 10 (23), 4839-44. 
(34) Hontorialucas, C.; Lopezpeinado, A. J.; Lopezgonzalez, J. D. D.; Rojascervantes, M. L.; Martinaranda, R. M. Study of oxygen-containing groups in a series of graphite oxides physical and chemical characterisation. Carbon 1995, 33 (11), 1585-1592.

(35) Withnall, R.; Andrews, L. FTIR spectra of the photolysis products of the phosphine ozone complex in solid argon. J. Phys. Chem. 1987, 91 (4), 784-797.

(36) Kang, J.; Wells, S. A.; Wood, J. D.; Lee, J. H.; Liu, X. L.; Ryder, C. R.; Zhu, J.; Guest, J. R.; Husko, C. A.; Hersam, M. C. Stable aqueous dispersions of optically and electronically active phosphorene. Proceedings of the National Academy of Sciences of the United States of America 2016, 113 (42), 11688-11693.

(37) Chen, W. F.; Yan, L. F.; Bangal, P. R. Chemical Reduction of Graphene Oxide to Graphene by Sulfur-Containing Compounds. J. Phys. Chem. C 2010, 114 (47), 19885-19890. (38) Zhou, X. J.; Zhang, J. L.; Wu, H. X.; Yang, H. J.; Zhang, J. Y.; Guo, S. W. Reducing Graphene Oxide via Hydroxylamine: A Simple and Efficient Route to Graphene. J. Phys. Chem. C 2011, 115 (24), 11957-11961.

(39) Chen, C. M.; Zhang, Q.; Huang, C. H.; Zhao, X. C.; Zhang, B. S.; Kong, Q. Q.; Wang, M. Z.; Yang, Y. G.; Cai, R.; Sheng Su, D. Macroporous 'bubble' graphene film via templatedirected ordered-assembly for high rate supercapacitors. Chem. Commun. 2012, 48 (57), 7149-51.

(40) Parvez, K.; Wu, Z. S.; Li, R.; Liu, X.; Graf, R.; Feng, X.; Mullen, K. Exfoliation of graphite into graphene in aqueous solutions of inorganic salts. J. Am. Chem. Soc. 2014, 136 (16), 6083-91.

(41) Liu, Y.; Li, Y.; Zhong, M.; Yang, Y.; Yuefang, W.; Wang, M. A green and ultrafast approach to the synthesis of scalable graphene nanosheets with $\mathrm{Zn}$ powder for electrochemical energy storage. J. Mater. Chem. 2011, 21 (39), 15449. 
(42) Wang, S.; Dryfe, R. A. W. Graphene oxide-assisted deposition of carbon nanotubes on carbon cloth as advanced binder-free electrodes for flexible supercapacitors. J. Mater. Chem. A 2013, 1 (17), 5279.

(43) Weng, Z.; Su, Y.; Wang, D.-W.; Li, F.; Du, J.; Cheng, H.-M. Graphene-Cellulose Paper Flexible Supercapacitors. Adv. Energy Mater. 2011, 1 (5), 917-922.

(44) Lin, Y.; Liu, F.; Casano, G.; Bhavsar, R.; Kinloch, I. A.; Derby, B. Pristine Graphene Aerogels by Room-Temperature Freeze Gelation. Adv. Mater. 2016, 28 (36), 7993-8000. 
For Table of Contents Only
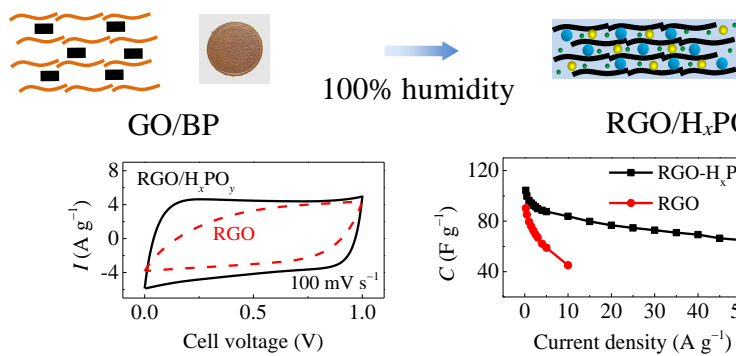

$\mathrm{RGO} / \mathrm{H}_{x} \mathrm{PO}$

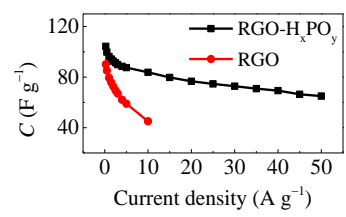

